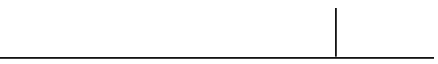

Rev. Latinoam. Psicopat. Fund., VIII, 4, 788-793

\title{
Dos males que acompanham 0 progresso do Brasil: a psiquiatria comparada de Juliano Moreira e colaboradores
}

\author{
Ana Maria Galdini Raimundo 0 da \\ Walmor Piccinini
}

A seção História da Psiquiatria deste número da Revista Latinoamericana de Psicopatologia Fundamental traz dois textos muito importantes que, embora escritos por brasileiros, são aqui pela primeira vez publicados em português. ${ }^{1}$

Trata-se de Les maladies mentales dans les climats tropicaux, de 1906, e de A contribution to the study of dementia paralytica in Brazil, de 1907.

Ambos artigos têm como principal autor o médico baiano Juliano Moreira (1873-1933), um dos fundadores da moderna psiquiatria brasileira; ele é acompanhado no primeiro por Júlio Afrânio Peixoto (1876-1947), também nascido na Bahia, médico legista, alienista, romancista e político destacado, e, no segundo, por Antonio Penafiel, médico gaúcho que foi alienista do Hospício Nacional e deputado federal.

Os trabalhos versam sobre aspectos da florescente disciplina que se chamava então psiquiatria comparada - mais tarde etnopsiquiatria,

1. Gostaríamos de ressaltar o empenho e de agradecer ao editor da Revista Latinoamericana de Psicopatologia Fundamental, Prof. Dr. Manoel Tosta Berlinck, que possibilitou a realização destas duas traduções e sua publicação. 
psiquiatria transcultural ou psiquiatria cultural - no caso, o estudo das relações entre doença mental, clima, raça e meio sociocultural.

Nesses textos, os autores defendem suas idéias a partir de relatos circunstanciados de casos clínicos por eles observados, demonstrando ainda que conheciam perfeitamente a produção científica internacional sobre o tema, e os pontos cruciais do debate etnopsiquiátrico.

Juliano Moreira dedicou-se com entusiasmo aos estudos de psiquiatria comparada no Brasil, campo em que produziu artigos e comunicações em congressos internacionais. ${ }^{2}$ Entre 1905 e 1906, ele se correspondeu com Emil Kraepelin, destacado estudioso da área, a respeito dos planos do professor alemão, que viria ao Brasil, junto com A. Alzheimer, para uma expedição de pesquisa etnopsicopatológica - expedição esta que acabou não ocorrendo, por motivos desconhecidos (Dalgalarrondo, 1996). ${ }^{3}$

Vale ressaltar que este alienista brasileiro se recusava a aceitar todas as proposições sobre a psicopatologia dos habitantes dos trópicos, especialmente sobre os negros e mestiços, que vinham dos europeus, colocando-se em posição intelectual de igualdade com os estrangeiros nesses debates.

Desta forma, J. Moreira criticava pelo menos três crenças dominantes na psiquiatria comparada do começo do século XX: primeiro, afirmava que não havia doenças mentais próprias dos climas tropicais; segundo, que a condição racial de um indivíduo não daria imunidade nem tampouco favoreceria o aparecimento de certas formas de insanidade mental; e, terceiro, recusava a tese da inferioridade intelectual nata do negro, atribuindo-a a fatores sociais e educacionais (Oda, Piccinini e Dalgalarrondo, 2005).

Entretanto, se divergiam de alguns pressupostos etnopsiquiátricos dos alienistas europeus, Moreira e colaboradores concordavam inteiramente com a

2. Listamos os seguintes trabalhos: a) Moreira, J.; Peixoto, A. Les maladies mentales dans le climats tropicaux. Archivos Brasileiros de Psychiatria, Neurologia e Sciencias Affins, II (1): 222-41, 1906; b) Moreira, J.; Penafiel, A. A contribution to the study of dementia paralytica in Brazil. Journal of Mental Science, 53: 507-21, 1907; c) Moreira, J.; Peixoto, A. Les maladies mentales au Brésil. Congresso Internacional de Psiquiatria, Amsterdam, 1907; d) Moreira, J. A new contribution to the study of dementia paralytica in Brazil. XVII Congresso Internacional de Medicina, Londres, 1913; e) Moreira, J. Notes sur quelques maladies nerveuses et mentales au Brésil. III Congresso Internacional de Neurologia e Psiquiatria, Gand, 1913; f) Moreira, J. Die Nerven und Geistskrankheiten in den Tropen. In: Mense, C. (ed.). Handbuch der Tropenkrankheiten, 1926; g) Moreira, J. Algo sobre doenças nervosas e mentais no Brasil. Revista Íbero-Americana, Hamburgo, n. 8, 1929.

3. As cartas de autoria de J. Moreira foram traduzidas e comentadas por Paulo Dalgalarrondo em seu livro Civilização e loucura: uma introdução à história da etnopsiquiatria. 


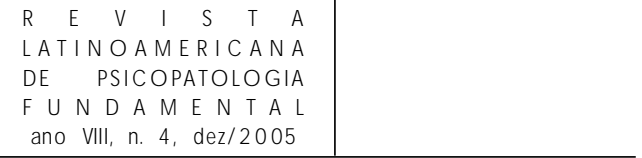

afirmação, repetida por quase todos os alienistas influentes depois de Esquirol, de que as exigências da vida civilizada e a superpopulação nas grandes cidades, a dissolução dos costumes, a pobreza urbana, o esgotamento físico e mental dos tempos modernos seriam causas desencadeantes de um suposto aumento nas taxas de doenças mentais (Oda, Banzato e Dalgalarrondo, 2005).

Era também consensual que as prevalências da dementia paralytica e da neurastenia, sobretudo, sofreriam especial influência do grau de civilização de um povo, e seriam tão mais freqüentes quanto maior o grau de progresso (leiase desenvolvimento capitalista) da região.

Às citadas vicissitudes do progresso se juntariam, para usar a expressão dos autores brasileiros, os excessos "de cibus, de potus e de vênus”, ou seja, excessos alimentares, alcoólicos e sexuais, comportamentos desmesurados que estariam relacionados à gênese das moléstias mentais.

Na avaliação de Moreira e colaboradores, no país as causas mais importantes das moléstias mentais seriam o alcoolismo, a sífilis, o impaludismo, as verminoses (sobretudo a ancilostomose), intoxicações diversas e os excessos e desvios sexuais. Eles observam ainda que estas seriam, na verdade, causas ocasionais ou desencadeantes, já que a verdadeira etiologia da maioria das doenças mentais permanecia motivo de especulação ou se atribuía à herança ou à degenerescência.

\section{A dementia paralytica e a sífilis}

Dementia paralytica, paralisia geral progressiva ou ainda paralisia dos alienados são termos usados como sinônimos da entidade clínica que configura um conjunto de perturbações neurológicas e psicopatológicas associadas, com evolução progressiva para um estado demencial.

A descrição de um quadro de paralisia progressiva em sujeitos alienados fora feita já no início do século XIX, especialmente pelos alienistas franceses Bayle e Calmeil. Entretanto, só a partir da segunda metade daquele século se postularia claramente sua relação com a sífilis.

Em 1905, Fritz Schaudinn demonstrou o agente infeccioso nas lesões genitais primárias e, em 1906, o primeiro exame laboratorial para detecção de sífilis no sangue foi desenvolvido por August von Wassermann. Apenas em 1913, Hydeyo Noguchi e J. W. Moore demonstraram a presença de espiroquetas (Treponema pallidum, bactéria causadora da sífilis) no cérebro de pacientes mentais com quadro clínico de paralisia progressiva, finalmente comprovando a sua etiopatogenia sifilítica (Ackerknecht, 1964; Alexander e Selesnick, 1980). 
Assim, compreende-se que, em 1907, Moreira e Peixoto considerem que cerca de $80 \%$ dos casos de dementia paralytica teriam origem sifilítica, deixando margem às possibilidades de outras etiologias tóxico-infecciosas para o quadro.

Recorde-se ainda que não havia tratamento efetivo para a neuro-sífilis até 1917, quando o médico vienense Wagner von Jauregg (1857-1940) começou a aplicar sistematicamente o tratamento de febre malárica (malarioterapia), cujos resultados expressivos renderam a von Jauregg o prêmio Nobel de Medicina de 1927. Como se sabe, apenas em meados do século XX surgiria um agente quimioterápico capaz de curar a infecção pela sífilis, a penicilina descoberta por Alexander Fleming (Alexander e Selesnick, 1980).

\section{Juliano Moreira e a sifiligrafia}

O interesse de Juliano Moreira pelo estudo da sífilis começou ainda como estudante; ele foi interno do Serviço Clínico de Dermatologia e Sifiligrafia da Faculdade de Medicina da Bahia, tendo se graduado com a tese Etiologia da sífilis maligna precoce (Moreira, 1891).

Na mesma Faculdade - antes de se transferir para o Rio de Janeiro, onde seria diretor, de 1903 a 1930, do Hospício Nacional de Alienados - ele trabalhou paralelamente nos campos da dermatologia e da neuropsiquiatria. Nestes trabalhos, aliava a descrição clínica detalhada e a comprovação anatomopatológica. O estudo de doenças sistêmicas graves, com potenciais manifestações cutâneas e neuropsiquiátricas, tais como a sífilis, a lepra e as intoxicações por arsênico, renderam-lhe várias publicações em revistas internacionais. Durante uma viagem de estudos na Europa (1900 a 1901), ligou-se a laboratórios e grupos de pesquisa em dermatologia e sifiligrafia, especialmente na Alemanha (Leme Lopes, 1964).

Assim, o artigo sobre a dementia paralytica no Brasil apresenta a visão de um especialista no tema, como indica a cuidadosa revisão das possíveis relações entre o desenvolvimento desta forma grave de sífilis do sistema nervoso central e fatores como raça, sexo, idade, estado civil, ocupação e tempo de doença. Memorável também é a investigação feita pelos autores, em 200 casos, dos sinais físicos característicos desta síndrome, referentes a anormalidades dos reflexos das pupilas, da pronúncia e do reflexo patelar (dos joelhos).

\section{A psiquiatria comparada nos trópicos}

Desde fins do século XVIII, vinha se desenvolvendo a geografia médica, um campo de estudo formado pela confluência de diversas áreas científicas, tais 


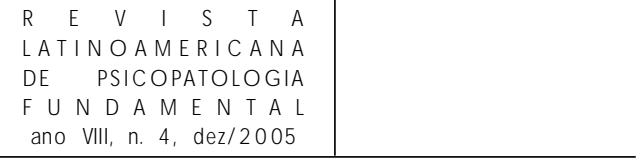

como a meteorologia, a topografia, a geologia e a medicina, que procurava descrever as chamadas patologias tropicais, em suas relações com o meio físico e climático das regiões quentes. ${ }^{4}$ Esta disciplina teve grande impulso, sobretudo, pelo interesse das potências coloniais européias em expansão, que desejavam desenvolver conhecimentos médicos patológicos e terapêuticos sobre os habitantes dos territórios que dominavam (Edler, 2001).

Prestigiosa, a geografia médica teve vários tratadistas famosos, cujas obras eram muito lidas e respeitadas, até o fim do século XIX. Assim, compreende-se o empenho de Moreira e Peixoto, no artigo sobre as moléstias mentais dos climas quentes, em refutar os argumentos de tais autoridades, a partir de uma perspectiva científica diversa, dizendo que "não existem doenças mentais climáticas, ou mais particularmente que, em climas quentes, não se observa nenhuma forma patológica que seja estranha à neuropsiquiatria dos outros climas”.

Estes autores assinalam ainda que, no Brasil, a lista das doenças mentais era a mesma de qualquer outro país, apenas se notavam variações na freqüência relativa do aparecimento de algumas delas. Neste interessante texto, eles deixam transparecer velhas questões, ainda em debate, sobre a etiologia das doenças mentais. Uma delas era já bem antiga: teriam as condições atmosféricas, ou as fases da lua, influência na evolução das doenças nervosas, sobretudo a epilepsia? Não, respondiam eles, informando que, ao estudarem minuciosamente a freqüência das crises dos epilépticos internados no Hospício Nacional, não encontraram correlação destas com as condições meteorológicas da cidade do Rio de Janeiro, tampouco com as fases da lua.

Depois de revisar a ocorrência das principais síndromes mentais no Brasil, baseados sobretudo nas estatísticas do Hospício Nacional, Moreira e Peixoto concluem que não há influência direta do clima ou da raça sobre os sintomas ou a evolução clínica de tais doenças. Eles pensam que é no grau de instrução dos indivíduos, principalmente, que residiria a explicação das diferentes manifestações sintomáticas. Também ressaltam que os indivíduos originários de países frios não sofreriam, necessariamente, uma ação negativa dos trópicos sobre seu sistema nervoso, morando em países quentes.

Finalmente, queremos assinalar, em ambos artigos ora republicados, a presença de uma mensagem implícita, inserida no correr das descrições clínicas

4. A partir da perspectiva da climatologia médica, relacionando clima, raça e patologias tropicais e tratando das peculiaridades da terra, das doenças e da população do Brasil, temos a importante obra do médico francês, naturalizado brasileiro, Joseph-François Xavier Sigaud, $D u$ climat et des maladies du Brésil ou statistique medicale de cet Empire, editada em Paris, em 1844. 
e dos argumentos: quando os autores brasileiros insistiam na igualdade das manifestações psicopatológicas, ocorressem elas em climas quentes ou frios, estavam recusando a imagem exótica da loucura nos países tropicais, que os alienistas europeus vinham construindo no decorrer do século XIX.

A tal visão estereotipada dos habitantes dos trópicos, os alienistas locais pareciam responder: somos todos igualmente humanos; portanto, enlouquecemos todos por motivos humanos, e não climáticos ou raciais.

\section{Referências}

Alexander, F. e Selesnick, S. História da psiquiatria. São Paulo: Ibrasa, 1980. p. 217. Ackerknecht, E. H. Breve historia de la psiquiatría. Buenos Aires: Universitária, 1964. p. 50.

Dalgalarrondo, P. Civilização e loucura: uma introdução à história da etnopsiquiatria. São Paulo: Lemos, 1996.

EdLer, F. C. De olho no Brasil: a geografia médica e a viagem de Alphonse Rendu. História, Ciências, Saúde - Manguinhos, Rio de Janeiro, volume VIII, suplemento, p. 925-43, 2001.

Leme Lopes, J. Juliano Moreira. Jornal Brasileiro de Psiquiatria, Rio de Janeiro, v. XIII, n. 1, p. 13-9, 1964.

Moreira, J. Etiologia da Sífilis Maligna Precoce. 1891. Tese (doutoramento [graduação] em medicina). Faculdade de Medicina da Bahia, Salvador: Tipografia Liguori \& C.

Moreira, J.; Peixoto, A. Les maladies mentales dans les climats tropicaux. Archivos Brasileiros de Psychiatria, Neurologia e Sciencias Affins, ano II, n. 3, p. 222-41, set./ 1906.

Moreira, J.; Penafiel, A. A contribution to the study of dementia paralytica in Brazil. Journal of Mental Science, v. LIII, p. 507-21, jul./1907.

Oda, A. M. G. R.; Piccinini, W.; Dalgalarrondo, P. Juliano Moreira (1873-1933): founder of scientific psychiatry in Brazil. American Journal of Psychiatry, v. 162, n. 4, p. 666, abr./2005.

Oda, A. M. G. R.; Banzato, C. E. M; Dalgalarrondo, P. Some origins of cross-cultural psychiatry. History of Psychiatry, v. XVI, n. 2, p. 155-69, jun./2005. 